\title{
Application of nanoparticles for strengthening wellbore cement-formation bonding
}

\author{
Mtaki Thomas Maagi and Gu Jun* \\ Department of Petroleum Engineering, Faculty of Earth Resources, China University of Geosciences, 430074 Wuhan, PR China
}

Received: 5 March 2020 / Accepted: 2 July 2020

\begin{abstract}
This study evaluates the wellbore shear bond strength of oil-well cement pastes containing nano$\mathrm{SiO}_{2}$ and nano- $\mathrm{TiO}_{2}$ particles with an average of $20 \pm 5 \mathrm{~nm}$ particle sizes. The nanoparticles were selected by weight of cement at proportions equivalent to 1, 2, 3 and 4\%. The findings demonstrated that nanoparticles significantly increased the shear bond strength, and the strength increase was dependent on the nanoparticle types, dosage and curing period of the specimens. Due to effective pozzolanic activity, nano- $\mathrm{SiO}_{2}$ provided higher shear bond strength compared to nano- $\mathrm{TiO}_{2}$. The specimens containing $3 \%$ nano- $\mathrm{SiO}_{2}$ cured for 28 days displayed the utmost shear bond strength results $(0.553 \mathrm{MPa})$. The optimal replacement dosage was $3 \%$ for all nanoparticles. The particle type did not affect the optimum nanoparticles replacement content. To examine the influence of nanoparticles on cement-formation bonding, a Scanning Electron Microscope (SEM), X-Ray Diffraction (XRD), and thermogravimetric technique were used.
\end{abstract}

\section{Nomenclature}

$\begin{array}{ll}\text { API } & \text { American Petroleum Institute } \\ \text { bwoc } & \text { By Weight Of Cement } \\ \text { C-S-H } & \text { Calcium Silicate Hydrate } \\ \text { d } & \text { Day } \\ \text { h } & \text { Hour } \\ \text { NS } & \text { NanoSilica } \\ \text { NT } & \text { Titania Particles } \\ \text { NP } & \text { NanoParticles } \\ \text { r/min } & \text { Revolution Per Minute } \\ \text { SEM } & \text { Scanning Electron Microscope } \\ \text { SWB } & \text { Simulated WellBore } \\ \text { TG } & \text { ThermoGravimetry } \\ \text { TGA } & \text { ThermoGravimetric Analysis } \\ \text { TN } & \text { Titania Nanoparticles } \\ \text { WBM } & \text { Water-Based Mud } \\ \text { W/C } & \text { Water to Cement ratio } \\ \text { XRD } & \text { X-Ray Diffraction }\end{array}$

\section{Introduction}

Oil-well cementing is performed to provide zonal isolation, i.e. to restrict the movement of the fluid across different formations. Besides, cement is pumped into the wells to

\footnotetext{
* Corresponding author: gujun@cug.edu.cn
}

provide structural support for the steel casings and to secure the casings against corrosive fluids [1]. After setting, the cement sheath should possess mechanical properties sufficient to withstand the loads and provide structural sustenance and zonal isolation $[2,3]$.

Nevertheless, formation fluid leakage has been described as a major challenge for oil and gas wells for a long period of time. The fluid leakage is related to the fluid flow through the wellbore section of the cemented annulus [4, 5]. Some of the consequences of fluid leakage in the wellbore include high costs of remediation, production and abandonment, as well as environmental effects [6]. Several studies have indicated that poor contact between cement and the formation leads to fluid leakage (Fig. 1). Globally, previous oil-well integrity reports indicate that $4.6 \%$ of the 316,000 wells surveyed in Alberta had leak problems [7]. Around 13-19\% of the producing wells and $37-41 \%$ of the injection wells encountered leakage in the North Sea's Norwegian region $[8,9]$. Furthermore, over 8,000 wells in the Gulf of Mexico exhibited gas migration problems [10].

The poor strength of the shear bond between cement and formation has been identified as the key reason for the leakage of fluids $[4-6,10]$. In oil-well cementing, the shear bond strength refers to the force required to initiate the movement of cement from rock formation or movement of the steel case in the cement sheath [11]. The least allowable shear bond strength for oil-well cement is $100 \mathrm{psi}$ (0.689 MPa), in compliance with the American Petroleum Institute (API) specification 10A [12]. In this regard, several studies are conducted regularly focusing primarily on 


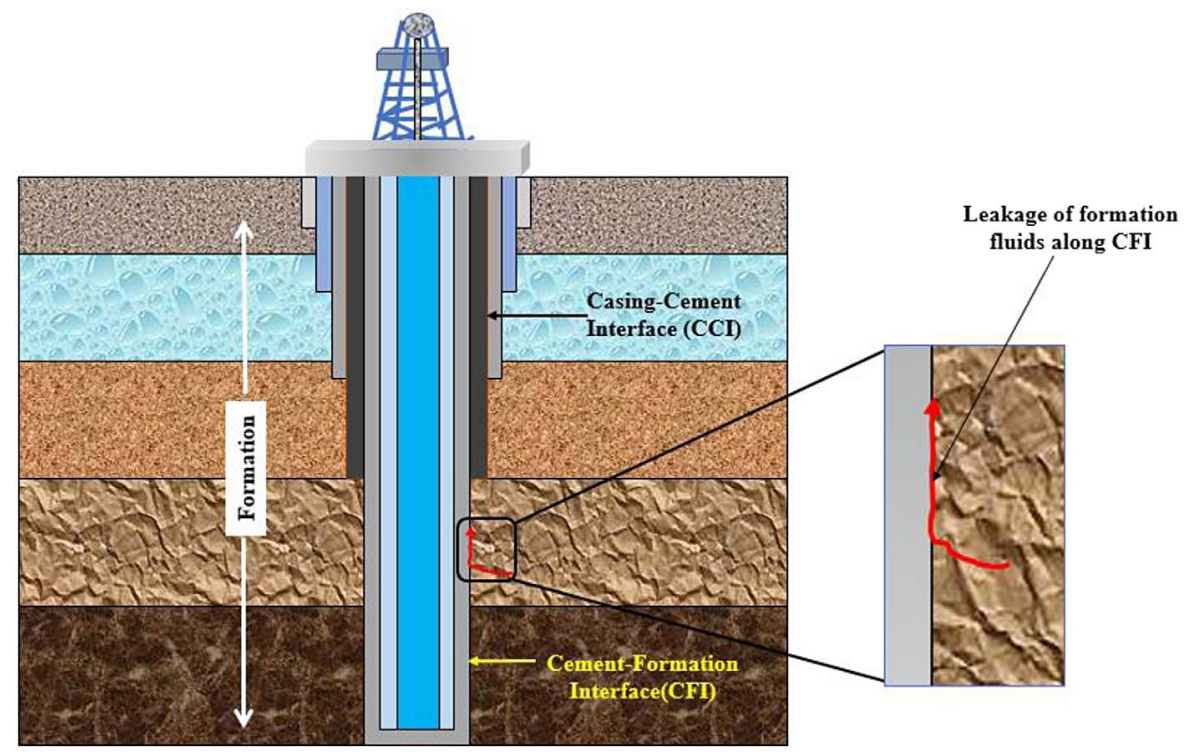

Fig. 1. The schematic diagram for fluid leakage along with the cement-formation interface due to poor cement bonding.

enhancing the bond strength at the cement-formation interface to boost well integrity and productivity [7, 13-15]. During the last few years, numerous researchers have concentrated on the use of nanoparticles to increase cement efficiency. In general, nanoparticles can impart functionality to cement by modifying various properties, such as early strength growth, long-term tensile increase to compressive strength ratio and microstructure improvement [16, 17]. Numerous types of nanoparticles such as nano- $\mathrm{SiO}_{2}$, nano- $\mathrm{Al}_{2} \mathrm{O}_{3}$, nano- $\mathrm{TiO}_{2}$, and $\mathrm{Fe}_{2} \mathrm{O}_{3}$ have been considered as cement additives [18-21].

Because of its nano-scale size, nanoparticles have exceptional properties that vary fundamentally with their macrosized counterparts [1]. In addition to their size effect, nanoparticles have special characteristics, including enormous surface area per volume ratio and higher chemical reactivity, which triggers their ability to modify cement properties [22-25]. It was reported that nano- $\mathrm{SiO}_{2}$ and nano- $\mathrm{Al}_{2} \mathrm{O}_{3}$ reduced the crystalline $\mathrm{Ca}(\mathrm{OH})_{2}$ amount and promoted the formation of Calcium Silicate Hydrate gel $(\mathrm{C}-\mathrm{S}-\mathrm{H})$, especially at an early age, which enhanced the strength of the cement [26]. Likewise, nano- $\mathrm{TiO}_{2}$ was reported to decrease the amount of $\mathrm{Ca}(\mathrm{OH})_{2}$ in hardened cement and stimulates the generation of $\mathrm{C}-\mathrm{S}-\mathrm{H}$ gels [27]. It was also reported that the abrasion resistance of cement composite containing nano- $\mathrm{SiO}_{2}$ and nano- $\mathrm{TiO}_{2}$ produced effective results, while nano- $\mathrm{TiO}_{2}$ showed the best performance compared to nano- $\mathrm{SiO}_{2}$ [28]. In Pang et al.'s work, it was reported that the use of nano- $\mathrm{SiO}_{2}$ powders containing 4-6 nm particle size would increase the compressive strength of oil-well cement by 30 and $136 \%$ within 2 and 7 days respectively. The effect of nanoparticles in cement mechanical strength was also demonstrated by Lee et al. [29]. They found that the compressive strength of Portland cement increased at $10 \%$ nano- $\mathrm{TiO}_{2}$ replacement by weight of cement (bwoc). In addition, Lee et al. revealed that nano$\mathrm{TiO}_{2}$ promotes cement hydration, and shortens the cement thickening time which in turn reduces the operational time and costs [29]. Similarly, the works of [30-32] confirmed the effect of nano- $\mathrm{SiO}_{2}$ on oil-well cement properties such as setting time, compressive strength and microstructure. These investigations acknowledged that the inclusion of nano$\mathrm{SiO}_{2}$ to cement slurry reduced the thickening time, increased compressive strength, and modified the hardened cement microstructure by depressing porosity and permeability.

Different authors [33-35] mention some potential nanoparticle mechanisms in cement. Firstly, the nano-scale size allows the use of nanoparticles as filler material by sealing the gaps in the cement matrix, resulting in a dense and compact structure with reduced capillary porosity. Secondly, nanoparticles have higher pozzolanic activity, making them the strongest cement hydration accelerators. Singh et al. [35] examined the effect of nano- $\mathrm{SiO}_{2}$ during hydration of cement and conclusively argued that the blending of nano- $\mathrm{SiO}_{2}$ into cement grains creates $\mathrm{H}_{2} \mathrm{SiO}_{4}{ }^{2-}$ that reacts with the existing $\mathrm{Ca}^{2+}$ to produce an excess C-S-H. Such C-S-H gelatin spread out among the cement grains in the water and act as nucleation sites for further compacted $\mathrm{C}-\mathrm{S}-\mathrm{H}$ gel formation. Thus, nano-SiO 2 powders can facilitate the pozzolanic reaction.

However, the incorporation of nanomaterials in cementbased materials has two specific challenges. One of these challenges is the dispersion of nanoparticles in a cement mixture. Some earlier researchers have reported that nanoparticle dispersion affects the workability of the cement slurry, the degree of hydration of cement and the mechanical properties of hardened cement. The previous reports concluded that the correct nanoparticle content has to be low (1-5\% bwoc) to avoid agglomeration of nanoparticles during blending, while some appealed that cement performance can also be enhanced with higher nanoparticle doses up to almost 10\% (bwoc) if nanoparticles are effectively distributed in the cement $[27,36]$. Liu et al. 
Table 1. Chemical and mineral composition of class G oil-well cement used.

\begin{tabular}{|c|c|c|c|c|c|c|c|c|c|}
\hline \multicolumn{5}{|c|}{ Chemical composition (wt\%) } & \multicolumn{5}{|c|}{ Mineralogical composition (wt\%) } \\
\hline $\mathrm{SiO}_{2}$ & $\mathrm{Al}_{2} \mathrm{O}_{3}$ & $\mathrm{Fe}_{2} \mathrm{O}_{3}$ & $\mathrm{CaO}$ & $\mathrm{MgO}$ & $\mathrm{SO}_{3}$ & $\mathrm{C}_{3} \mathrm{~S}$ & $\mathrm{C}_{2} \mathrm{~S}$ & $\mathrm{C}_{4} \mathrm{AF}$ & $\mathrm{C}_{3} \mathrm{~A}$ \\
\hline 23.056 & 2.86 & 3.52 & 65.2 & 1.79 & 2.12 & 59.890 & 16.756 & 10.70 & 1.63 \\
\hline
\end{tabular}

[37] established that smaller size and higher content of nano-powders can promote the cement hydration. On the contrary, nanoparticles combine easily due to van der Waals's force of attraction and electrostatic interaction, which greatly decreases the fluidity and strength of the cement matrix. Several researchers have discussed the reduction of slurry fluidity with the addition of nanoparticles as one of the troublesome issues of nano-additives in cementitious materials. Additionally, Bera et al. [26] examined the rheology of cement slurries and noted that the blending of nano-SiO $\mathrm{S}_{2}$ into cement significantly rises the water requirement in the mix to maintain its workability.

In spite of the widespread research of NanoParticles (NP) on cement properties recently, studies on the effect of nanomaterials on strengthening wellbore shear bond strength for successful zonal isolation are rarely found. Thus, this article aims to examine the influence of Nano$\mathrm{SiO}_{2}$ (NS) and Nano-TiO 2 (NT) on the wellbore cementformation interaction. X-Ray Diffraction (XRD), ThermoGravimetric Analysis (TGA), and Scanning Electron Microscope (SEM) techniques were used to verify NS and NT pozzolanic behavior and the microstructure adjustment of the bonded cement-formation interface.

\section{Experimental program}

\subsection{Materials}

The materials used in this work were; Class G oil-well cement, corresponded to API Specification 10A, (produced by Jiahua Enterprises Corp., Sichuan China, its clinker compositions are presented in Tab. 1), NS and NT particles (purchased from Guangzhou Probing Fine Chemical Co., $L t d$, China). The technical specifications of the nanoparticles are provided in Table 2. During cement slurry blending a dispersing agent made of polymerized and modified methane and acetone from Henan Xinxiang No. 7 Chemical Co., Ltd (Henan, China) was used to decrease the friction between particles and achieve better NP dispersion. The research had also used Water-Based Mud (WBM) acquired from Jianghan Oilfield in China, and Simulated WellBores (SWB) with $18 \%$ and $150 \times 10^{-3} \mu^{2}$ porosity and permeability respectively.

\subsection{Mix proportions}

The cement slurry formulation is provided in Table 3 . The NS and NT particles (1, 2, 3 and 4\%) by weight of solid (cement + nanoparticle) were combined with the Class G Oilwell cement. The water-to-cement ratio $(\mathrm{W} / \mathrm{C})$ was fixed at 0.45 of all mixtures. Furthermore, an appropriate amount of dispersants was applied for all mix ratios based on the weight of NP to achieve the desired flowability of the slurry.

\subsection{Experimental procedures}

\subsubsection{Slurry preparation}

The concept of cement pastes followed the API [38]. Blending practices were performed in a constant speed mixer according to the procedures described in previous research [37], as follows; First, cement and NP were put into the mixing pot and agitated for $2 \mathrm{~min}$. Afterward, the dispersant was dissolved in the mixing water. The aqueous solution for blending was then poured into the mixer. The cement pastes were blended at a low-speed $(4000 \mathrm{r} / \mathrm{min}$ for $15 \mathrm{~s}$, then at a high speed of $12000 \mathrm{r} / \mathrm{min}$ for $35 \mathrm{~s}$ according to API 10A standards) [38]. Upon completion of these mixing steps, the slurry appeared homogeneous. The rheological test was conducted to determine the flowing nature of the design slurry (Supplementary Materials $\mathrm{S} 1$ and S2).

\subsubsection{Rheological measurements}

The dial readings were recorded under different rotational speeds of $600,300,200,100,6$, and $3 \mathrm{rpm}$ respectively. The effect of NS and NT particles on the rheological properties of the slurry was determined using a ZNN-D6 rotational viscometer, manufactured by Qingdao Haitongda Equipment Corp., China. Readings were recorded first in ascending order and then in descending order at various rotational speeds $(\theta)$. The measurements are reported as an average of the ramp-up and ramp-down readings. The flow behavior index $(n)$ and consistency coefficient $(k)$ of the slurry were calculated as follows;

$$
\begin{gathered}
n=2.096 \log \left(\frac{\theta_{300}}{\theta_{100}}\right), \\
k=\frac{0.511 \theta_{300}}{511^{n}}
\end{gathered}
$$

where $\theta_{300}$ is the reading at a shear rate of $300 \mathrm{rpm}$, and $\theta_{100}$ is the reading at the shear rate of $100 \mathrm{rpm}$. A larger " $n$ " indicates a better slurry fluidity while a larger " $k$ " indicates a thicker slurry.

\subsubsection{Preparation of SWB}

The SWB specimens of about $6.5 \mathrm{~cm}$ height and diameter of $3.3 \mathrm{~cm}$ were made using quartz sand, cement and water (Fig. 2B). Then, the WBM was employed to mimic the borehole mudcake after sealing the SWB on one side using a glass plate with butter. Mud was applied to the borehole until it was fully and maintained for $4 \mathrm{~h}$ to allow the cake to be formed before emptied out. It was noticed that a mudcake film was stuck to the surface of the borehole. Using 
Table 2. Properties of nanoparticles.

\begin{tabular}{lccccc}
\hline Species & Average diameter $(\mathrm{nm})$ & Color & Specific surface area $\left(\mathrm{m}^{2} / \mathrm{g}\right)$ & $\mathrm{pH}$ value & Purity $(\%)$ \\
\hline $\mathrm{SiO}_{2}$ & $20 \pm 5$ & White & $220 \pm 5$ & 5.7 & 99.9 \\
$\mathrm{TiO}_{2}$ & $20 \pm 5$ & White & $160-180$ & 6.8 & 99.9 \\
\hline
\end{tabular}

Table 3. Mixing proportions for each experimental test.

\begin{tabular}{lccccc}
\hline Batch & Water $(\mathrm{g})$ & Cement $(\mathrm{g})$ & Nanoparticles $(\mathrm{g})$ & W/C ratio & Dispersant (wt\% NP) \\
\hline CO 0\% & 354 & 792 & 0 & 0.45 & 0 \\
NT 1\% & 354 & 784.08 & 7.92 & 0.45 & 0.50 \\
NT 2\% & 354 & 776.16 & 15.84 & 0.45 & 1.00 \\
NT 3\% & 354 & 768.24 & 23.76 & 0.45 & 1.50 \\
NT 4\% & 354 & 760.32 & 31.68 & 0.45 & 2.00 \\
\hline
\end{tabular}

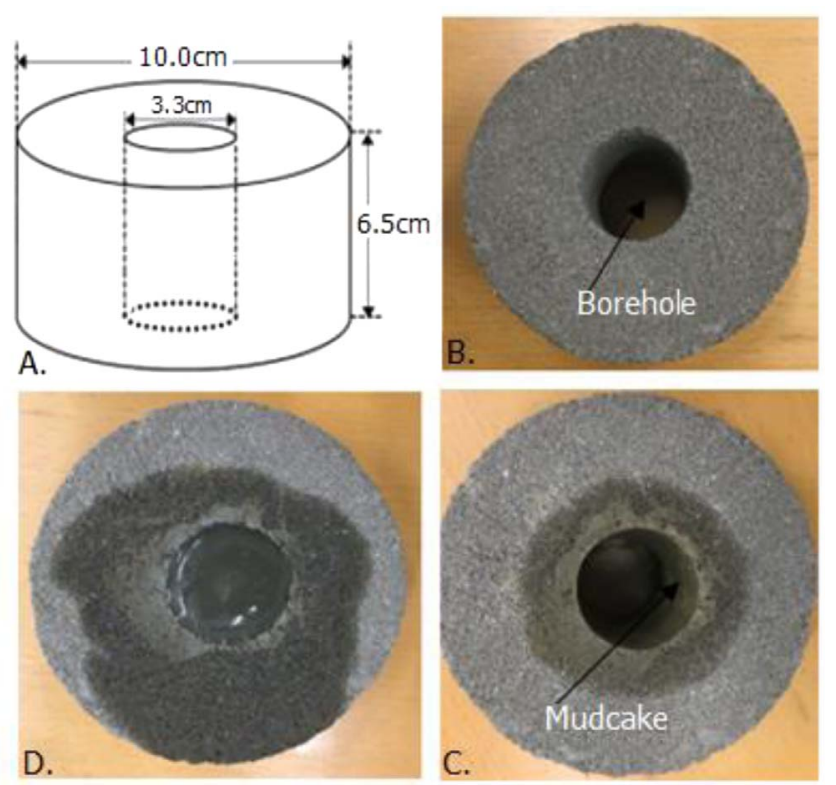

Fig. 2. (A) Simulated wellbore design. (B) Simulated wellbore. (C) Mudcake formation. (D) Cement slurry injection.

the glass stick the produced mudcake was scraped out of the wall to achieve the thinness set for this study, $0.5 \mathrm{~mm}$ (Fig. 2C). The designed cement slurry was then introduced into the SWBs to bond the cement-formation interaction (Fig. 2D). Lastly, the specimens were taken in a curing chamber set at a temperature of $80{ }^{\circ} \mathrm{C}$ for $3,7,14$, and 28 days, followed by shear force measurement using a WDW - Y10A Universal testing machine.

\subsubsection{Determining shear bond strength}

The push-out test of the cement-formation bond was achieved to determine the shear force from which shear bond strength was calculated. During the test, the steel indenter was hard-pressed downwards at the speed of $0.5 \mathrm{~mm} / \mathrm{s}$ to induce failure at the cement-formation interface. The load cell configuration for this test was $10 \mathrm{kN}$.
When the ultimate force on cement stone was attained, the cement-formation interface was demolished, and the shear force was carefully recorded. Then, the sheer force was divided by the interfacial cross-sectional area to obtain the shear bond strength as displayed in equation (3):

$$
P=\frac{10 F}{\pi h D}
$$

where, $P=$ shear bond strength at the cement-formation interface $(\mathrm{MPa}), F=$ interfacial shear force $(\mathrm{KN})$, $h=$ height of the SWB $(\mathrm{cm}), D=$ inner diameter of the SWB $(\mathrm{cm})$. Figure 3 indicates the schematic diagram for the shear bond strength test.

\subsubsection{SEM investigation}

This work adopted SEM to examine the microstructures of the bonded cement-formation interface. SEM examination was conducted on a Quanta200 machine developed by Holland FEI (Hong Kong) Co., Ltd. Several fragments were collected by forceps during the strength tests and held for $6 \mathrm{~h}$ in ethanol to stop the hydration. Before scanning, the specimens were put in an oven set at $60{ }^{\circ} \mathrm{C}$ for $24 \mathrm{~h}$ to remove any outgassing from organic contaminants and water. The specimens were then placed on the holders with double-sided, conductive gold tapes. The imaging method for the Back-Scattered Electron (BSE) was used to examine the samples that were mounted under the situation to ensure their respective analytical capacity.

\subsubsection{TGA material characterization}

The TGA material characterization was performed using the detailed STA 409 PC model of the thermal analyzer instrument. First, the crushed specimens were stored in ethanol for $6 \mathrm{~h}$ to stop the hydration process. The specimens were then placed in an oven set at $60^{\circ} \mathrm{C}$ for $24 \mathrm{~h}$ to dry. The dried samples were ground into a powder form using a hard porcelain pestle and mortar. The weight of each sample was set to be $50 \mathrm{mg}$. With a heating rate of $20^{\circ} \mathrm{C} / \mathrm{min}$, the temperature gradually increased from room temperature to $1000{ }^{\circ} \mathrm{C}$, keeping it stable at $1000{ }^{\circ} \mathrm{C}$ for $2 \mathrm{~h}$. During the 


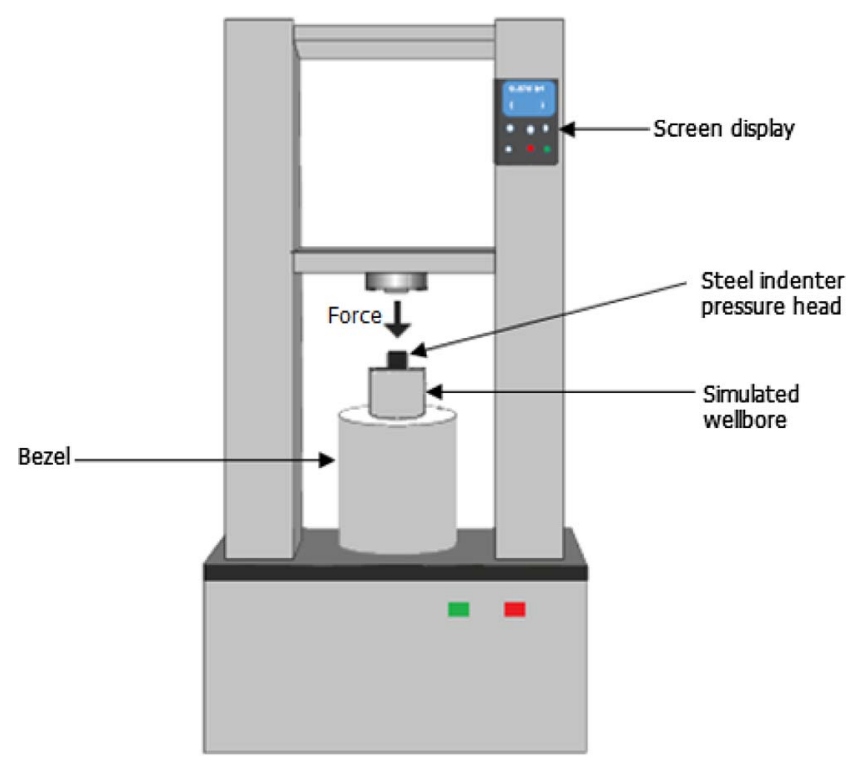

Fig. 3. The schematic diagram for the shear bond strength test.

heating process, the tests were conducted at atmospheric pressure with a $20 \mathrm{~mL} / \mathrm{min}$ nitrogen flow in the chamber to prevent the specimens from being carbonized during the study.

\subsubsection{XRD analysis}

XRD has been used to study portlandite reductions during pozzolanic action. The specimens were assembled and ground into powdered form before initiating the XRD test. About $1 \mathrm{~g}$ sample was sufficient for each XRD measurement. To determine the phase of cement samples, a D8-Focus X-ray diffractometer (produced by Bruker $A X S$ $\mathrm{GmbH}$, Germany) was used, fitted with a $40 \mathrm{kV}$ and $40 \mathrm{~mA}$ LynxEye detector and graphite-monochromatized $\mathrm{CuK} \alpha$ radiation using the Nickel filter. The measurements were carried out in an angular range $2 \theta$ of $5-70^{\circ}$ and a scanning step was $0.01^{\circ} \min ^{-1}$ [39]. In Jade Software, X-ray diffractograms were analyzed with the control of computers directly connected to the diffractometer.

\section{Results and discussion}

\subsection{Influence of NS and NT particles on rheological properties}

Tables 4 and 5 present the influence of NT and NS dosages on the rheology of the oil-well cement slurry. The results reveal that the apparent viscosities of the slurry at all shear rates have a slight variation after the addition of NS and NT into the cement. The results also show a rise in the consistency coefficient $k$ and a decline of the fluidity index $n$, indicating that after incorporation of NS and NT the cement slurry becomes poorer. The cement slurry becomes much heavier with the addition of NS and NT.

The results revealed that the NS particles with a higher specific surface area $\left(220 \pm 5 \mathrm{~m}^{2} / \mathrm{g}\right)$ made the slurry slightly thicker than NT particles with a specific surface area of the 160-180 $\mathrm{m}^{2} / \mathrm{g}$. Liu et al. [37] identified that the incorporation of NS and NT in cemented materials decreases the workability since NS and NT particles absorb part of the blending water. Thus, water molecules are freely drawn towards the NS and NT powders due to enormous surface area and greater reactivity.

Alternatively, Berra et al. [40] studied the rheology of cement slurries and noted that mixing nanoparticles into cement significantly increases the need for water in the mix to maintain its fluidity. Some authors reported that, if the water content in the mixture is preserved, an increase in NP content would facilitate the packaging of materials that positively decrease free water [33].

\subsection{The effect of nanoparticle types and content on shear bond strength}

The shear bond strength for the specimens with variable dosages of NP was determined after being cured at $80{ }^{\circ} \mathrm{C}$ for a period of $3,7,14$, and 28 days. Figures 4 and 5 show the shear bond strength results obtained from various samples composed of NS, and NT nano-powders respectively. It can be evidently seen that the interfacial shear bond strength of the specimens composed of nanoparticles is significantly higher than the shear bond strength of the control specimens.

As concisely summarized in Figures 4 and 5, the shear bond strength increased gradually depending on the type of NP. The curing ages of the specimens also influenced the shear bond strength. The results indicate that shear bond strength improved progressively as the curing time was increased. The ultimate values of shear bond strength were attained after 28 days of curing. In comparison, the slurries having NS enhanced the shear bond strength more significantly than the specimens composed of NT particles. Overall, NS powders presented excellent results at all curing ages likened to compared NT nano-additives. This might be due to the reason that NS is the most effective pozzolanic additive than NT. The addition of NS into cement grains increases the consumption of $\mathrm{Ca}(\mathrm{OH})_{2}$ and creates an extra $\mathrm{C}-\mathrm{S}-\mathrm{H}$ gels formation which is the main element for strength in hardened cement [33, 41].

In addition, Figures 4 and 6 display the tendency of shear bond strength by fluctuating the dosages of NS and NT particles. The results indicate that the interfacial shear bond strength was improved by the increasing dosages of NP indicating that these nano-scale materials are capable of boosting the interaction between cement and formation for improved zonal isolation. Generally, in all contents of $\mathrm{NP}$, the interfacial bonding strength was improved continuously until the nanoparticle dosage of $3 \%$, which exhibited the maximum cement-formation bond strength. Based on the results it was revealed that the optimal replacement content of NP was $3 \%$ bwoc. In other words, lower or higher contents than the optimal replacement $(3 \%)$ can result in reduced shear bond strength compared to that of the optimal amount. The lower NP proportions (1 and 2\%) are not efficient in stimulating the pozzolanic reaction. Therefore, the strengths of their corresponding shear bond are slightly 
Table 4. Effect of NT on the rheological properties.

\begin{tabular}{|c|c|c|c|c|c|c|c|c|c|c|}
\hline \multirow[t]{2}{*}{ No. } & \multirow[t]{2}{*}{ NT (\%) } & \multirow[t]{2}{*}{$\mathrm{W} / \mathrm{C}(\%)$} & \multicolumn{6}{|c|}{ Shear rate $(\mathrm{rev} / \mathrm{min})$} & \multirow[t]{2}{*}{$n$} & \multirow[t]{2}{*}{$k$} \\
\hline & & & 600 & 300 & 200 & 100 & 6 & 3 & & \\
\hline 1 & 0 & 0.45 & 134 & 93 & 81 & 63 & 23 & 17 & 0.355 & 5.193 \\
\hline 2 & 1 & 0.45 & 166 & 123 & 90 & 85 & 21 & 18 & 0.336 & 7.732 \\
\hline 3 & 2 & 0.45 & 241 & 155 & 126 & 108 & 27 & 20 & 0.329 & 10.178 \\
\hline 4 & 3 & 0.45 & 248 & 168 & 139 & 117 & 31 & 25 & 0.329 & 11.032 \\
\hline 5 & 4 & 0.45 & 255 & 168 & 142 & 118 & 34 & 27 & 0.321 & 11.597 \\
\hline
\end{tabular}

Table 5. Effect of NS on the rheological properties.

\begin{tabular}{|c|c|c|c|c|c|c|c|c|c|c|}
\hline \multirow[t]{2}{*}{ No. } & \multirow[t]{2}{*}{ NS (\%) } & \multirow[t]{2}{*}{$\mathrm{W} / \mathrm{C}(\%)$} & \multicolumn{6}{|c|}{ Shear rate $(\mathrm{rev} / \mathrm{min})$} & \multirow[t]{2}{*}{$n$} & \multirow[t]{2}{*}{$k$} \\
\hline & & & 600 & 300 & 200 & 100 & 6 & 3 & & \\
\hline 1 & 0 & 0.45 & 134 & 93 & 81 & 63 & 23 & 17 & 0.355 & 5.193 \\
\hline 2 & 1 & 0.45 & 167 & 112 & 87 & 85 & 19 & 16 & 0.306 & 8.489 \\
\hline 3 & 2 & 0.45 & 148 & 153 & 124 & 107 & 25 & 18 & 0.325 & 10.300 \\
\hline 4 & 3 & 0.45 & 139 & 167 & 137 & 115 & 29 & 23 & 0.339 & 10.303 \\
\hline 5 & 4 & 0.45 & 122 & 168 & 140 & 117 & 32 & 25 & 0.329 & 11.032 \\
\hline
\end{tabular}

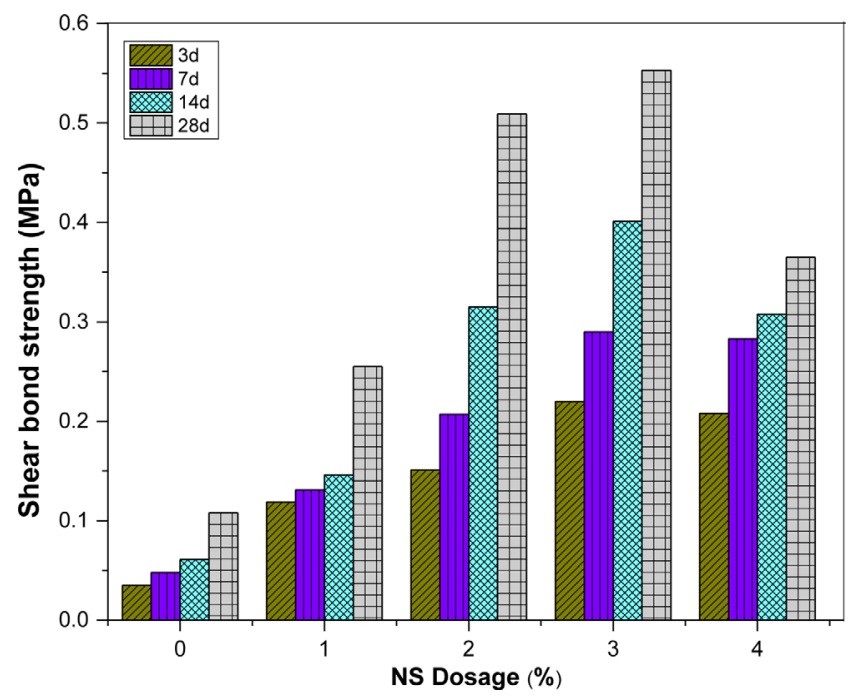

Fig. 4. Shear bond strength of the cement-formation interface containing NS particles.

increased. On the other hand, the pozzolanic activity is likely to be promoted through the incorporation of NS and NT particles with extreme content (4\%). Nevertheless, the actual mass of cement in the mix will gradually decrease, allowing cement to inactively hydrate. The decrease in rates of hydration could have been greater than the pozzolanic reaction progressions. Thus, lesser shear bond strengths were achieved with $4 \%$ relative to the optimum replacement content (3\%). This conclusion presented strong correlations with the findings of the previous work of Haruehansapong et al. [27]. The study also found that the overuse of NS and NT particles in cement impedes the uniform dispersal of particles. The optimal content of NP in

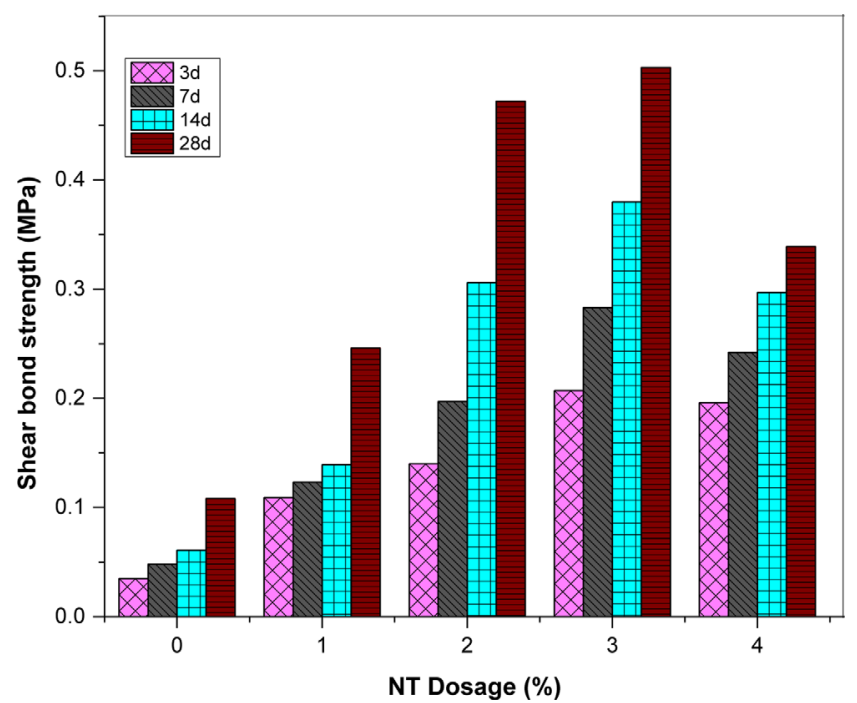

Fig. 5. Shear bond strength of the cement-formation interface containing NT particles.

cement, however, cannot be determined with a certain proportion. It was established that the optimal replacement content of NP in cement depends on several factors including the nature of nanomaterial either dry powder or colloidal $[35,41]$.

\subsection{Material characterization techniques}

\subsubsection{SEM analysis}

SEM experiments were conducted to verify the mechanism of why NS and NT particles enhance the shear bond strength. Figure 6 shows the SEM image for the pure 


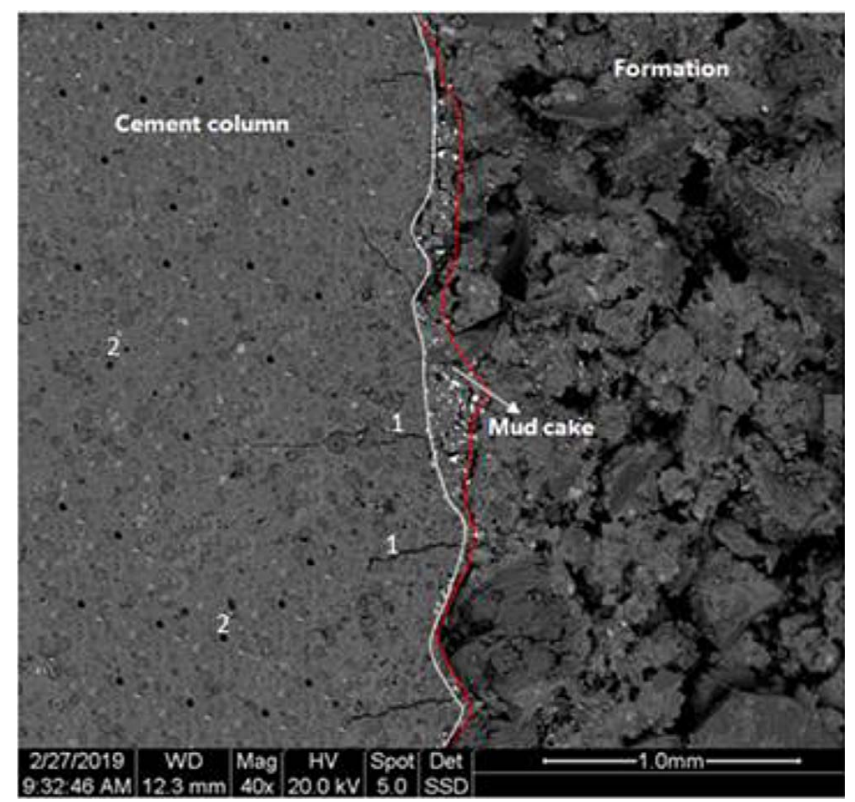

Fig. 6. SEM photograph for the pure cement-formation interface cured for 14 days $(1=$ fractures, $2=$ pores $)$.

cement column and the formation cured in 14 days. As seen from the micrograph, the formation and cement column boundaries appear clear. Several pores are also observed within the cement formation interface. Shrinkage cracks along the interface extending to the cement column emerged due to a change in the moisture of cement and mud. The cement and mud tend to expand when they absorb the water and shrink when they dry causing shrinkage micro-cracks.

Indeed, there is a peeling phenomenon which indicates that the affinity to mudcake-cement is very weak. Mudcake is loosely attached to the cement column, indicating that the interfacial bond strength between the two surfaces is weak, making it an easy route for fluid movement. This finding coincides with the shear bond strength results.

Figures 7 and 8 present the SEM photographs for the specimens composed of $3 \%$ NT and NS respectively cured in 14 days. The images confirm that the NS and NT nano-additives significantly affect the microstructure of the cement-formation interface. It is evidently seen that there was an improvement of the bonded microstructure of the cemented interface between the simulated formation and the hardened cement column. The pores within the cement sheath and along the interfaces are very small and the distribution is relatively uniform compared to the conventional cement samples. In addition, there is no peeling phenomenon between the mudcake and the cement. The cement and formation interface is closely bonded, suggesting that NS and NT can significantly improve the affinity between the two interfaces, promoting the solidification of the mudcake and cement column, thereby enhancing the shear bond between the cement and formation. However, there are minor fissures along with the interface containing NS and NT particles (Fig. 7). Due to the filler effect of nanoparticles, it was expected that all the pores would be

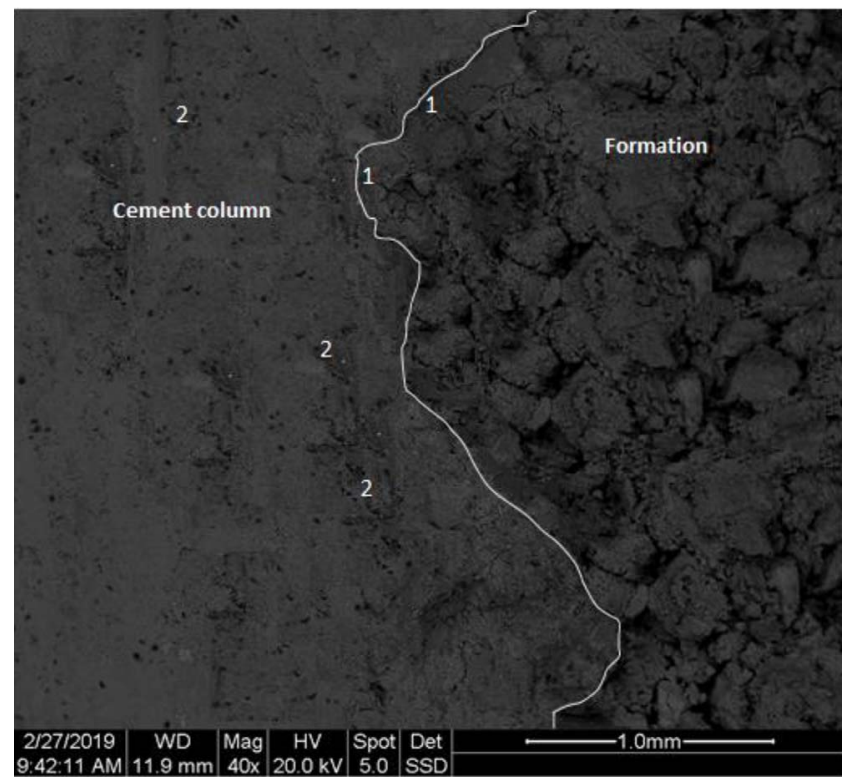

Fig. 7. SEM photograph for the cement-formation interface containing $3 \%$ NT particles cured for 14 days $(1=$ fissures, $2=$ pores $)$.

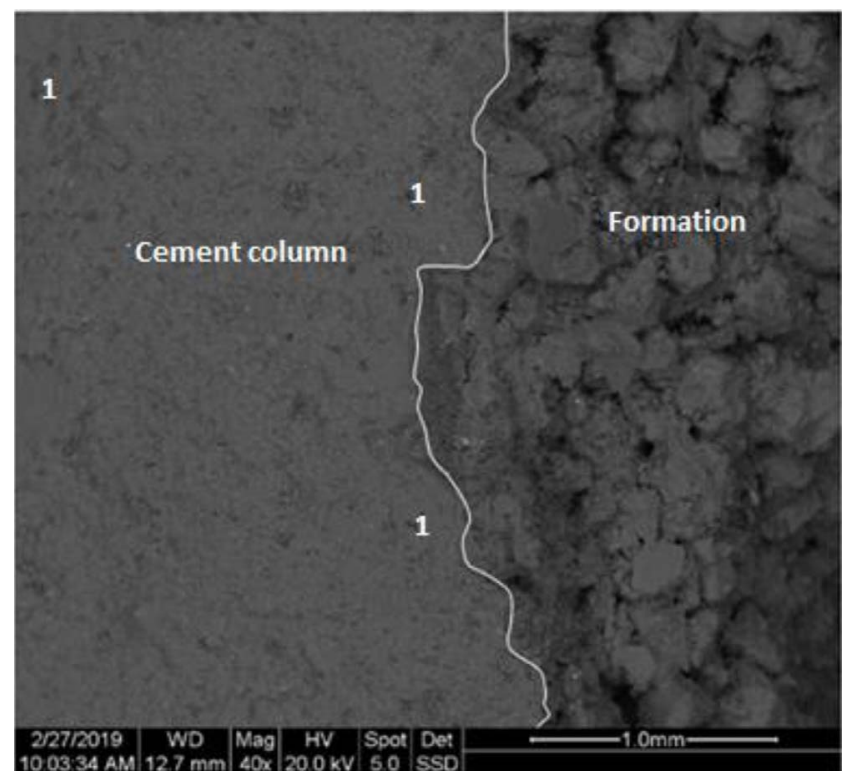

Fig. 8. SEM photograph for the cement-formation interface containing $3 \%$ NS particles cured for 14 days ( $1=$ small pores $)$.

filled especially at this content of NP. As the micrograph shows, very small openings still exist within the cement column and at the interface. The reason for this could be due to the large surface area of NP that leads to agglomeration especially at higher contents of the incorporated nanomaterials, inhibiting the uniform distribution of the particles with the cement matrix [41].

On the other hand, the microstructure of the bonded interface comprising NS appears denser, with more uniform textures compared to samples containing NT (Fig. 8). This 
shows that NS is a more effective nanomaterial for packing efficiency and uniform distribution in the cement paste. NS may produce extra $\mathrm{C}-\mathrm{S}-\mathrm{H}$ gels during cement hydration due to its higher pozzolanic activity $[29,42]$. The $\mathrm{C}-\mathrm{S}-\mathrm{H}$ gels plug in the openings, thus the mudcake and cement particles are closely linked together, producing a very uniform integrated compact structure, thereby maximizing the cement strength of the two interfaces.

\subsubsection{TGA results}

Figure 9 displays the ThermoGravimetry (TG) graphs of cement containing NT and NS respectively, after 28 days of curing. Once subjected to a progressive thermal environment ranging from room temperature to $1000{ }^{\circ} \mathrm{C}$, the TG curves show the normal reactions in cement paste. When subjected to rising temperatures, the weight loss in the cement paste specimens occurred primarily in three phases. Firstly, at room temperature up to $200{ }^{\circ} \mathrm{C}$, weight loss was due to the dehydration of water molecules in hydrated cement materials such as $\mathrm{C}-\mathrm{S}-\mathrm{H}$ and ettringite (calcium sulphoaluminate hydrate) [43, 44].

As seen from the graph, the percentage increase in weight loss demonstrates the increasing amount of hydration materials produced. The effect of NS and NT particles on accelerating hydration of cement has been confirmed. Due to the pozzolanic nature of NS and NT, NS and NTcontaining specimens exhibited higher weight loss compared to control samples, suggesting that more C-S-H gels were formed in NP-containing samples. Nonetheless, specimens containing NT particles showed less weight loss compared to samples containing NS. Based on the results, NS particles are suitable materials in-terms of pozzolanic reactivity, which corresponds to the shear bond strength results obtained.

The second temperature decomposition occurred between $325{ }^{\circ} \mathrm{C}$ and $550{ }^{\circ} \mathrm{C}$. The relative mass loss was due to $\mathrm{Ca}(\mathrm{OH})_{2}$ thermal degradation in this temperature range $[36,45,46]$. The increasing percentage of weight loss at this stage was due to the produced $\mathrm{Ca}(\mathrm{OH})_{2}$. In the control samples, the biggest weight loss was seen compared to specimens with NS and NT at this interval. This scenario also confirmed the reaction of NS and NT as pozzolanic additives. The $\mathrm{Ca}(\mathrm{OH})_{2}$ 's pozzolanic reaction with NP creates more $\mathrm{C}-\mathrm{S}-\mathrm{H}$ gel which is the chief element of strength buildup in cementitious materials. That reaction, in other words, converts $\mathrm{Ca}(\mathrm{OH})_{2}$ to $\mathrm{C}-\mathrm{S}-\mathrm{H}$ gels. Therefore, the reason for the plain samples having a higher percentage weight loss at this interval is because pozzolanic activity which decreases the quantities of $\mathrm{Ca}(\mathrm{OH})_{2}$ in the hardened cement happened only in the nanoparticles containing samples. On the other hand, the specimens composed of NS provided the minimum percentage in mass loss due to effectual pozzolanic action, compared to samples containing NT.

The third period of thermal decomposition appeared between $550-740{ }^{\circ} \mathrm{C}$, due to calcium carbonate $\left(\mathrm{CaCO}_{3}\right)$ degradation and carbon dioxide gas $\left(\mathrm{CO}_{2}\right)$ emission from the cement-based materials. Literature report that during cement curing, $\mathrm{Ca}(\mathrm{OH})_{2}$ produced during cement hydration gradually combines with $\mathrm{CO}_{2}$ from the surrounding to form $\mathrm{CaCO}_{3}$ [47]. At this level, the control samples displayed

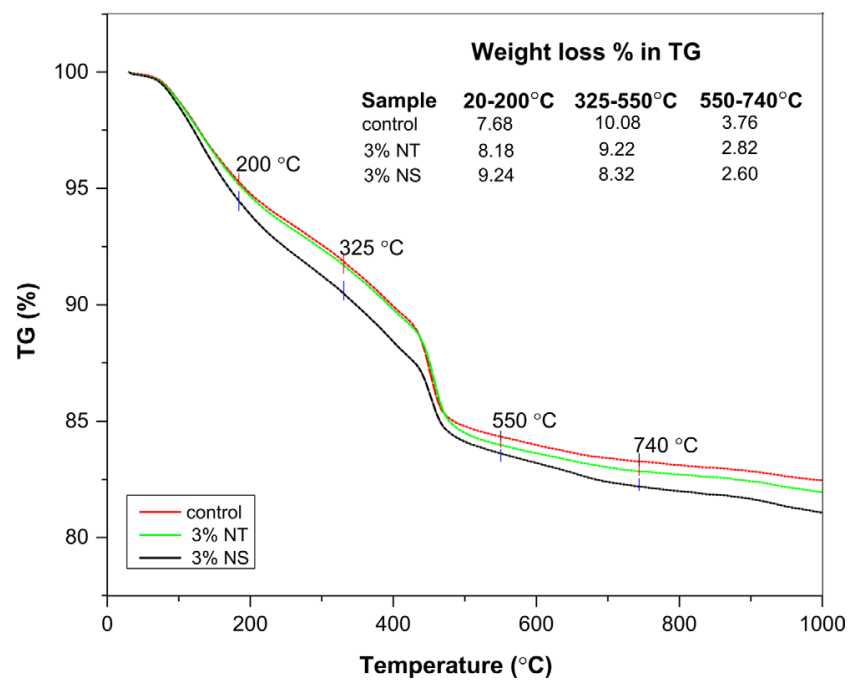

Fig. 9. TG curves of the hardened cement composed of NT and NS $(3 \%)$ cured for 28 days.

higher $\mathrm{CO}_{2}$ content compared to the specimens made up of NS and NT, which released a small amount of $\mathrm{CO}_{2}$ due to their pozzolanic effect.

\subsubsection{Portlandite $\left(\mathrm{Ca}(\mathrm{OH})_{2}\right)$ consumption}

Figure 10 shows XRD diffractograms for NS and NT modified cement specimens consisting of nanoparticle and the reference samples. A 14-day XRD test confirmed the consumption of Portlandite $\mathrm{Ca}(\mathrm{OH})_{2}$, after a $3 \% \mathrm{NS}$ and NT cement replacement. The presence of $\mathrm{Ca}(\mathrm{OH})_{2}$ suggests that a cement hydration reaction occurred. It can be seen from the diffractograms that plain cement produces $100 \%$ of $\mathrm{Ca}(\mathrm{OH})_{2}$, and this amount of $\mathrm{Ca}(\mathrm{OH})_{2}$ declines based on the type of NP in cement. In this case, NS particles induced a greater reduction of $\mathrm{Ca}(\mathrm{OH})_{2}$ compared to NT, which meant that NS particles had higher pozzolanic activity than NT particles. The specimens containing NS and NT particles decreased the amount of $\mathrm{Ca}(\mathrm{OH})_{2}$ by 36.53 and $20.85 \%$ respectively with the equal replacement content of $3 \%$. In other words, NS and NT nanomaterials converted part of the $\mathrm{Ca}(\mathrm{OH})_{2}$ crystals into gadolinite which is a silicate-based material, thus generating more $\mathrm{C}-\mathrm{S}-\mathrm{H}$ for enhanced strength. The XRD test results showed that the higher the pozzolanic material, the higher the gadolinite content and thus the more $\mathrm{C}-\mathrm{S}-\mathrm{H}$ gels. In particular, what causes the greater formation of $\mathrm{C}-\mathrm{S}-\mathrm{H}$ gel is the higher consumption of $\mathrm{Ca}(\mathrm{OH})_{2}$ that occurs during cement hydration. The rate of consumption of $\mathrm{Ca}(\mathrm{OH})_{2}$ also depends on the pozzolanic activity of the NP incorporated in cement. Because of its greater pozzolanic nature, NS generated more C-S-H gel as a result of NS reaction with $\mathrm{Ca}(\mathrm{OH})_{2}$ which reduces the content of $\mathrm{Ca}(\mathrm{OH})_{2}$ while promoting the shear bond strength.

The huge surface area of NS $\left(220 \pm 5 \mathrm{~m}^{2} / \mathrm{g}\right)$ would have plenty of quantum sized pores and tunnels, resulting in noticeable surface reactivity. NS particles, therefore, acted as nucleating agents and facilitated hydration of $\mathrm{C}_{3} \mathrm{~S}$ and $\mathrm{C}_{2} \mathrm{~S}$ to generate an influential quantity of $\mathrm{C}-\mathrm{S}-\mathrm{H}$ gel 


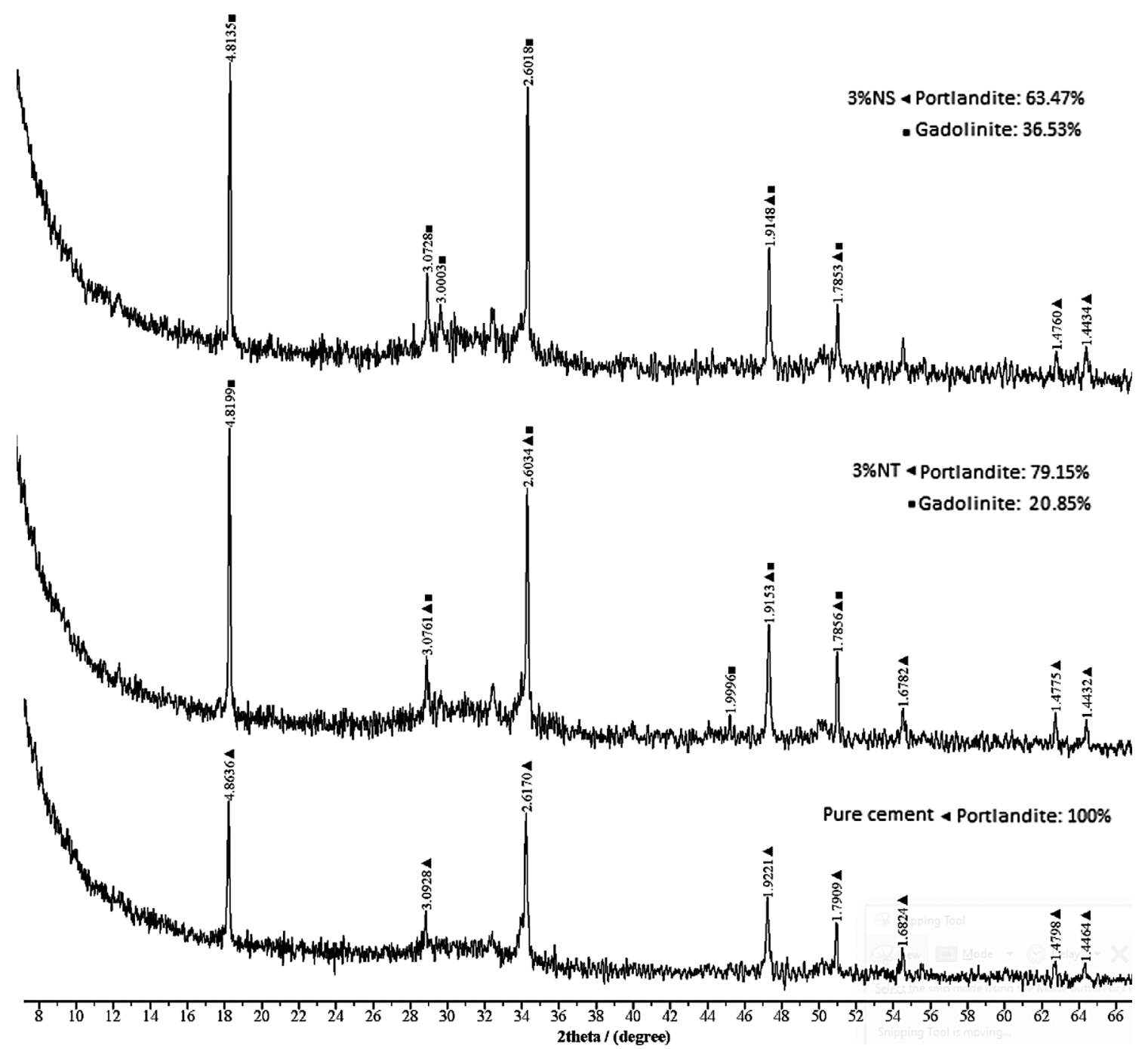

Fig. 10. XRD cement diffractograms showing $\mathrm{Ca}(\mathrm{OH})_{2}$ consumption after 14 days of cure, with and without nanoparticles.

compared to NT. NS also had multiple active sites on their enormous surfaces, such as broken $\mathrm{Si}-\mathrm{O}-\mathrm{Si}$-bonds, resulting in a very large pozzolanic reactivity and a significantly increased amount of free $\mathrm{C}$ bonds formed [36]. The XRD analysis, therefore, reveals that NS nanomaterial has a superior pozzolanic potential than a corresponding percentage of NT powder $(3 \%)$. The results of the XRD tests are in strong agreement with the cement-formation shear bond strength data.

\section{Conclusion}

In this work, NS and NT nanomaterials were used to investigate the effect of nanoparticles on the wellbore shear bond strength at the cement-formation interface. The following statements are made, based on the results:

1. The findings demonstrated that nanoparticle straightly affects the wellbore shear bond strength at the cement-formation interface. The NS addition provided the highest shear bond strength equivalent to NT particles. The plausible reason is due to the effectiveness of NS in the pozzolanic activity.

2. Based on the NP type and curing times, the shear bond strength of the NS and NT-containing specimens increased with the accumulative NP content. After 28 days of curing, NS provided the maximum bonding strength at a dosage of $3 \%$.

3. The optimum dosage of NS and NT particles in cement was found to be $3 \%$ for this study. The type of NP did not have any effect on the optimum replacement content.

4. SEM images revealed that NS and NT particles can alter the microstructure of hardened cement, making the structure more compact and denser, provided the NP content is adequate and distributed equitably.

5. NP pozzolanic reactivity was verified by tracking the variability in the quantity of $\mathrm{Ca}(\mathrm{OH})_{2}$ and $\mathrm{CaCO}_{3}$ from the second and third TG analytical intervals. 
The XRD study also included the pozzolanicity test. NS particles were a suitable nanomaterial type that delivered the best results in terms of pozzolanic activity.

\section{Supplementary Materials}

Supplementary material is available at https://ogst.ifpenergiesnouvelles.fr/10.2516/ogst/2020052/olm

Supplementary Material S1. Experimental procedures.

Supplementary Material S2. Descriptive statistics of the results.

Acknowledgments. This work was supported by the National Natural Science Foundation of China (grant No. 41972326 and 51774258).

\section{References}

1 Fakoya M.F., Shah S.N. (2017) Emergence of nanotechnology in the oil and gas industry: Emphasis on the application of silica nanoparticles, Petroleum 3, 391-405.

2 Nelson E.B., Guillot D. (2006) Well cementation, Developments in petroleum science book series, Schlumberger.

3 Yang J., Ji S., Qin W., Lu Y. (2015) Advances of nanotechnologies in oil and gas industries, Energy Explor. Exploit. 33, 5, 639-657.

4 Agbasimalo N. (2012) Experimental study of the effect of drilling fluid contamination on the integrity of cementformation interface, MSc Thesis, Department of Pet. Eng., Louisiana State University, USA.

5 Agbasimalo N., Radonjic M. (2012) Experimental study of portland cement/rock interface in relation to wellbore stability for Carbon Capture and Storage (CCS), in: 46th U.S. Rock Mechanics/Geomechanics Symposium, American Rock Mechanics Association, Chicago, Illinois, 9 p.

6 Agbasimalo N., Radonjic M. (2014) Experimental study of the impact of drilling fluid contamination on the integrity of cement-formation interface, J. Energy Res. Tech. 136, 4, 042908 .

7 Taoutaou S., Goh S.H., Bermea J.A.V., Vinaipanit M., McClure J. (2015) Achieving zonal isolation by using newgeneration mud removal chemistry and design methodology to displace non-aqueous drilling fluid, Society of Petroleum Engineers.

8 Nygaard R. (2010) Well design and well integrity. Wabamun area $\mathrm{CO}_{2}$ sequestration project. Energy and Environmental Systems Group.

9 Watson T.L., Bachu S. (2007) Evaluation of the potential for gas and $\mathrm{CO}_{2}$ leakage along wellbores, in: EEP Environmental and Safety Conference, Galveston, Texas, USA.

10 Radonjic M., Oyibo A. (2014) Experimental evaluation of wellbore cement-formation shear bond strength in presence of drilling fluid contamination, in: 5th Int. Conf. on Porous Media and Their Applications in Science, Eng. \& Indust. Eds, ECI Symposium Series.

11 Dwight K.S. (1990) Cementing, Second printing, SPE, New York City.
12 API10A (2010) Specification for cements and materials for well cementing, 24th edn, American Petroleum Institute.

$13 \mathrm{Gu}$ J. (2009) Isolation problems of cement-formation interface and scientific conception of mud cake to agglomerated cake, J. Oil Gas. Technol. 31, 1, 71-74.

14 Haiyang H., Jun G., Ju H., Zhongwu W., Qinggui W., Yikun Z., Wenlong W. (2016) Comparative study on cementation of cement-mudcake interface with and without mud-cakesolidification-agents application in oil and gas wells, J. Pet. Sci. Eng. 147, 143-153.

15 Opedal N., Todorovic J., Torsaeter M., Vralstad T., Mushtaq W. (2014) Experimental study on the cement-formation bonding, SPE.

16 Santra A.K., Boul P., Pang X. (2012) Influence of nanomaterials in oilwell cement hydration and mechanical properties, in: SPE International Oilfield Nanotechnology Conf. $\mathcal{G}$ Exh., Noordwijk, The Netherlands.

17 Yuan H., Shi Y., Xu Z., Lu C., Ni Y., Lan X. (2014) Effect of nano-MgO on thermal and mechanical properties of aluminate cement composite thermal energy storage materials, Ceram. Int. 40, 3, 4811-4817.

18 Quercia G., Brouwers H.J.H., Garnier A., Luke K. (2016) Influence of olvine nanosilica on hydration and performance of oil-well cement slurries, Mater. Design 96, 162-170.

19 Jafariesfad N., Gong Y., Geiker M.R., Skalle P. (2016) Nanosized $\mathrm{MgO}$ with engineered expansive property for oilwell cement systems, in: Proceedings of the SPE Bergen One Day Seminar, Grieghallen, Bergen, Norway, 20 April 2016, Society of Petroleum Engineers, Richardson, TX, USA.

20 Agista M., Guo K., Yu Z. (2018) A state-of-the-art review of nanoparticles application in petroleum with a focus on enhanced oil recovery, Appl. Sci. 8, 871, 1-29.

21 Senff L., Hotza D., Lucas S., Ferrera V.M., Labrincha J.A. (2012) Effect of nano- $\mathrm{SiO}_{2}$ and nano- $\mathrm{TiO}_{2}$ addition on the rheological behavior and the hardened properties of cement mortars, Mater. Sci. Eng. A 532, 354-361.

22 Amanullah M., Al-Tahini A.M. (2009) Nanotechnology- its significance in smart fluid development for oil and gas field, in: SPE Saudi Arabia Section Technical Symposium, SPE.

23 Patil R., Deshpande A. (2012) Use of nanomaterials in cementing applications, in: SPE International Oilfield Nanotechnology Conference and Exhibition, 12-14 June, SPE, Noordwijk, The Netherlands.

24 Senff L., Hotza D., Repette W.L. (2010) Rheological characterization of cement pastes with nanosilica, silica fumes and superplasters additions, Adv. Appl. Ceram. Struct. Funct. Bioceram. 109, 213-218.

25 Stefanidou M. (2012) Influence of nano- $\mathrm{SiO}_{2}$ on the portland cement pastes, Compos. Part B Eng. 43, 2706-2710.

26 Qing Y., Zenan Z., Li S. (2006) A comparative study on the pozzalonic activity between nano-silica and silica fumes, $J$. Wuhan Univ. Tech. Mat. Sci. 21, 153-157.

27 Haruehansapong S., Pulngern T., Chucheepsakul S. (2014) Effect of the particle size of nanosilica on the compressive, strength and the optimum replacement content of cement mortar containing nano-SiO ${ }_{2}$, Construct. Build. Mater. 50, 471-477.

28 Li H., Xiao H., Yuan J., Ou J. (2004) Microstructure of cement mortar with nano-particles, Compos. Part B Eng. 35, $185-189$.

29 Lee B.Y., Jayapalan A.R., Kurtis K.E. (2013) Effects of nano- $\mathrm{TiO}_{2}$ on properties of cement-based materials, Mag. Concr. Res. 65, 21, 1293-1302. 
30 El-Diasty A.I., Ragab A.M.S. (2013) Applications of Nanotechnology in the Oil \& Gas Industry: Latest Trends Worldwide \& Future Challenges in Egypt, in: North Africa Technical Conference and Exhibition, Society of Petroleum Engineers, Cairo, Egypt, p. 13.

31 Ershadi V., Ebadi T., Rabbani A.R., Ershadi L., Soltanian H. (2011) The effect of nanosilica on cement matrix permeability in oil well to decrease the pollution of receptive environment, Int. J. Environ. Sci. Dev. 2, 128-132.

32 Nabhani N., Emami M., Moghadam A. (2011) Application of nanotechnology and nanomaterials in oil and gas industry, AIP Conference Proceedings 1415, pp. 128-131.

33 Chithra S., Kumar S., Chinnaraju K. (2016) The effect of colloidal nano-silica on workability, mechanical and durability properties of high performance concrete with copper slag as partial fine aggregate, Constr. Build. Mater. 113, 794804.

34 Khayati G.H., Ghasabe H.M., Karfarma M. (2015) A survey on the application of oxide nanoparticles for improving concrete processing, Adv. Concr. Constr. 3, 2, 145-159.

35 Singh L.P., Karade S., Bhattacharyya S., Yousuf M.M., Ahalawat S. (2013) Beneficial role of nanosilica in cement based materials - A review, Constr. Build. Mater. 47, 10691077.

36 Biricik H., Sarier N. (2014) Comparative study of the characteristics of nano silica, silica fume- and fly ashincorporated cement mortars, Mater. Res. 17, 570-582.

37 Liu J., Li Q., Xu S. (2015) Influence of nanoparticles on fluidity and mechanical properties of cement mortar, Constr. Build. Mater. 101, 892-901.

38 API10A (2010) Specification for cements and materials for well cementing, 24th edn, American Petroleum Institute.
39 Carvalho I.P., Sousa R.B., Matos J.M.E., Moura J.V.B., Freire P.T.C., Pinheiro G.S., Luz-Lima C. (2020) Lowtemperature induced phase transitions in BaWO4:Er3+ microcrystals: A Raman scattering study, J. Mol. Struct. 1204, 127498.

40 Berra M., Carassiti F., Mangialardi T., Paolini A.E., Sebastiani M. (2012) Effects of nanosilica addition on workability and compressive strength of Portland cement pastes, Constr. Build Mat. 35, 666-675.

41 Silvestre J.P.T. (2015) Nanotechnology in construction: Towards structural applications, MSc Thesis, Lisbon University Technology, Lisbon, Portugal.

42 Wang C., Chen X., Wei X. (2017) Can nanosilica sol prevent oil-well cement from strength retrogression under high temperature? Constr. Build. Mater. 144, 574-585.

43 Abo-El-Enein S.A., El-Gamal S.M.A., Aiad I.A., Azab M.M., Mohamed O.A. (2016) Early hydration characteristics of oil well cement pastes admixed with newly prepared organic admixture, HBRC 14, 2, 207-214.

44 Scrivener K.L., Kirkpatrick R.J. (2008) Innovation in use and research on cementitious material, Cem. Concr. Res. 38, 2, 128-136.

45 Mleza Y., Hajjaji M. (2012) Microstructural characterisation and physical properties of cured thermally activated claylime blends, Constr. Build. Mater. 26, 226-232.

46 Frias M., Cabrera J. (2001) Influence of MK on the reaction kinetics in MK/lime and MK-blended cement systems at $20{ }^{\circ} \mathrm{C}$, Cem. Concr. Res. 31, 519-527.

47 Chang C.F., Chen J.W. (2006) The experimental investigation of concrete carbonation depth, Cem. Concr. Res. 36, $1760-1767$. 